\section{Asthma and pregnancy}

\author{
KE Lewis and P Ebden
}

increased tidal volume, but not respiratory rate). This is thought to be due to increased progesterone levels aggravated by diaphragmatic splinting from the increased volume of the gravid uterus.

Differential diagnosis of dyspnoea also includes pulmonary emboli presenting as bronchospasm (especially if 'asthma' presents for the first time in pregnancy, other risk factors, evidence of DVT or previous thrombotic episodes) and other cardiopulmonary disorders.

\section{General management}

The general principles of asthma treatment in pregnancy are identical to non-pregnant patients. It is essential that a multidisciplinary approach is taken, to include respiratory nurses, respiratory physicians and obstetricians, with the GP and practice nurse playing pivotal roles.

\section{EFFECT OF ASTHMA ON PREGNANCY}

Differences in the pattern of asthma in pregnancy could be due to maternal hypoxia causing foetal hypoxia and / or other physiological effects of poorly controlled asthma. There may be effects of drug toxicity (see below) or other factors associated with asthma, but not directly due to the disease itself or treatment, for example asthmatic women may have a generalised effect of smooth muscle hyper-responsiveness causing uterine and vascular, as well as bronchial, constriction.

Maternal effects include increased prevalence of preeclampsia. ${ }^{4}$ Asthmatic women also have an increased risk of antepartum and postpartum haemorrhage independent of medication usage. ${ }^{2}$ The foetus may be indirectly affected because maternal hypoxia results in hyperventilation and respiratory alkalosis. This can cause hypocarbic uterine vasoconstriction and a shift in the maternal oxygen dissociation curve to the left. Both of these factors may result in foetal hypoxia, premature birth, low birth weight, and congenital malformations. ${ }^{4}$ Greenberger's ${ }^{5}$ and Jana's ${ }^{6}$ studies suggest (but do not prove) that the control of asthma, rather than drug side-effects or other associated pathology, is the most important predictor of a good outcome. They demonstrated that mothers whose asthma was sufficiently well controlled not to require emergency therapy, gave birth to children who weighed significantly more than children whose mothers needed hospital admission - but there are potential confounders. There is increased foetal growth (birth weight) when asthma is well controlled during pregnancy as assessed by better and more stable lung function. Finally, the incidence of adverse foetal outcomes in asthmatics was the same as non-asthmatics when managed by asthma specialists ${ }^{7}$ although the largest studies only included 500 asthmatics. ${ }^{8}$ \section{Dr KE Lewis}

Correspondence to: klewis@doctors.org.uk

Date received: 01/12/99 Date accepted: 20/01/00

\section{GENERAL MEASURES \\ Diagnosis}

There are many causes of shortness of breath in hyperventilation of pregnancy (no wheeze and pregnancy, probably the most common is physiological
Smoking should be vigorously discouraged and the importance of regular home PEF monitoring, assessment for the most appropriate delivery device and compliance with medication cannot be over emphasized. Any known triggers (tobacco smoke, pets and allergies) need to be avoided. PEF charts and written self-management plans for treating both acute or chronic asthma could be provided by a health professional early on in the pregnancy.

When considering drug delivery, inhalation has particular advantages in pregnancy. Local therapeutic action can be achieved without the need for plasma concentrations liable to have a pharmacological effect on the foetus, or being influenced by changes in protein-binding and pharmacodynamics.

\section{DRUGS USED IN ASTHMA WHEN PREGNANT $\beta_{2}$-agonists}

$\beta_{2}$-agonists are the mainstay of treatment when attacks are infrequent; providing rapid relief, they can be used on occasion prophylactically, such as before exercise or exposure to colder outdoor air. Maternal sideeffects include fine tremor, palpitations, headache and nervous tension. ${ }^{9}$ Peripheral vasodilatation, tachycardia and hypokalaemia may also occur. There is little to choose between terbutaline or salbutamol, although most experience has been with the latter. Fenoterol is less $\beta_{2}$-selective and, therefore, may have more side-effects and is not recommended. Foetal side-effects in animal studies have demonstrated harmful effects only if used at very high doses early on in pregnancy, but no adverse consequence have been demonstrated in humans over the many years $\beta_{2 \text {-agonists have been used. }}{ }^{10,11}$

Salmeterol and eformoterol are long-acting $\beta_{2}$-agonists with similar side-effects to salbutamol. It should be emphasized to the patient that co-existing steroids should not be withdrawn. Information on long-acting $\beta_{2}$-agonists in pregnancy is limited and although others 
have commented on their use, ${ }^{12}$ the British National Formulary and manufacturers advise that they are to be used only if potential benefit outweighs risk.

\section{Inhaled corticosteroids}

These are the chosen prophylactic anti-inflammatory agent where symptoms are more frequent. In a Finnish study, 47 of a total of 457 pregnant asthmatics had attacks. A significant proportion (17\%) of asthmatics had an acute attack if not on inhaled steroids but only $4 \%$ if they used inhaled steroids. ${ }^{10}$ As less is known about fluticasone and budesonide than beclomethasone in pregnancy, beclomethasone would be recommended as first choice, however, the woman could continue her routine steroid inhaler as before, if she falls pregnant.

Maternal side-effects are the same as found in nonpregnant women and include occasional oral candidiasis and hoarse voice at high-dose, this can be reduced by using a spacer (and rinsing the mouth). High-dose inhaled steroids have been shown to alter markers of bone metabolism, but there is no clear association with osteoporosis. The dose should be just sufficient to control the asthma. There have been few foetal side-effects documented.

\section{Systemic corticosteroids}

Systemic corticosteroids may be needed for managing acute severe asthma, and when symptoms are not controlled on high-dose inhaled steroids and $\beta_{2}$-agonists. Asthmatic women taking oral steroids are at increased risk of pregnancy-induced hypertension (odds ratio of 1.7), ${ }^{2}$ and in a large, prospectively monitored cohort of 824 pregnant women with asthma, oral steroids were independently associated with pre-eclampsia $(p=0.027),{ }^{11}$ this has also been confirmed by others. ${ }^{2}$ The mechanism is unknown.

Foetal side-effects may include a two-fold increased risk of neonatal hyperbilirubinaemia. ${ }^{2}$ Animal studies have highlighted species-specific abnormalities, for example mice have developed cleft palates and rabbits cardiac anomalies, however humans seem unaffected by systemic steroid exposure in utero. ${ }^{10,11}$ Maternal doses of $10 \mathrm{mg}$ or more of prednisolone can result in foetal exposure of $1 \mathrm{mg}$ or more of the drug (crosses placenta slowly so maternal: foetal ratio is approximately 10:1). This can cause neonatal adrenal suppression so the newborn should be closely monitored for adrenal insufficiency immediately postbirth due to a sudden withdrawal of circulating steroid when the cord is cut. We recommend a paediatrician be present at birth and hydrocortisone given to the newborn if needed. To cover the extra stress in a woman who is adrenally suppressed from prolonged treatment with steroids (greater than one month), we also recommend that the mother receive intravenous hydrocortisone during labour and delivery.

Most studies suggest that severe asthma is associated with maternal and foetal morbidity and mortality, the risk-benefit ratio is clearly in favour of corticosteroids when needed.

\section{Anticholinergic bronchodilators}

Ipratropium and oxitropium bromide can be used as bronchodilators with $\beta_{2}$-agonists, ipratropium can be nebulised in severe attacks. Maternal side-effects include rare reports of dry mouth and constipation. There is no known teratogenecity shown in animals or humans, but they can cause foetal tachycardia and so should be used with caution in pregnancy.

\section{Sodium cromoglycate and nedocromil sodium} Both act prophylactically to stabilise mast cells and help prevent release of inflammatory mediators. They are inhaled before exercise, cold air or occupational exposure in susceptible individuals. Maternal sideeffects are few. No major congenital malformations on the foetus are reported in animals or humans ${ }^{10,11}$ with sodium cromoglycate, but experience is very limited with nedocromil sodium.

\section{Methylxanthines (theophyllines)}

This class of drugs is believed to act by phosphodiesterase inhibition and increasing intracellular cyclic AMP, they also have an immunomodulatory effect on T-cell lymphocytes important in the acute and chronic inflammatory reaction. Their use in pregnancy is controversial, but they can help nocturnal and early morning asthma. The pharmacokinetics of theophyllines are poorly understood in pregnancy with variable metabolism, protein-binding and hence plasma levels. If used, we recommend regular plasma level monitoring.

General maternal side-effects include nausea, upper gastrointestinal symptoms, cramps and palpitations. There is a theoretical risk that phosphodiesterase inhibition can cause uterine smooth muscle relaxation and prolong labour, but there is no clinical evidence that this occurs.

Theophylline crosses the placenta easily and there have been reports ${ }^{16}$ of neonates showing signs of theophylline toxicity (irritability and even apnoea) so care should be taken, especially during the third trimester. If intravenous aminophylline is used to manage an acute attack, lower loading doses are recommended. Maternal levels directly reflect foetal levels. There are reports of teratogenicity in animals, but not humans. ${ }^{3,11}$

\section{Leukotriene antagonists}

Montelukast and zafirlukast have only been recently developed and there is little experience on use in pregnancy. Their manufacturers recommend use only if essential and 'potential benefit outweighs risk'. ${ }^{9}$ They are generally well tolerated during pregnancy, but have caused headaches, gastrointestinal disturbances, hypersensitivity and upper respiratory tract infections.

Animal studies have not reported teratogenicity with montelukast and zafirlukast, but data for zileuton are less reassuring and so it should be avoided in pregnancy. ${ }^{4}$

\section{ACUTE ATTACK}

Pregnant women have died from acute asthma. If the attack is relatively mild and promptly treated, there is no serious adverse effect on pregnancy, delivery or health of newborn child. ${ }^{10}$ Treatment strategies are identical to non-pregnant patients, with nebulised $\beta_{2}$-agonists, systemic steroids and high-dose oxygen 
Table 1: Possible side-effects associated with asthma medication taken in pregnancy

$\begin{array}{ll}\text { Medication } & \text { Possible consequences to pregnancy } \\ \beta_{2} \text {-agonists (short-acting) } & \text { Animal studies - harmful to foetus in very high doses } \\ \beta_{2} \text {-agonists (long-acting) } & \text { No real evidence of harm, but experience limited } \\ \text { Oral corticosteroids } & \text { Animal studies - cleft palate and intrauterine growth retardation at high doses } \\ & \begin{array}{l}\text { Foetal/neonatal adrenal suppression at doses }>10 \mathrm{mg} \text { prednisolone; } \\ \text { reduced production of maternal cortisol with doses of }>7.5 \mathrm{mg} \\ \text { prednisolone } \\ \text { i.v. corticosteroids required during labour }\end{array} \\ & \text { Safe in pregnancy } \\ \text { Anticholinergics } & \text { Foetal tachycardia } \\ \text { Sodium cromoglycate/nedocromil } & \text { No adverse effects documented with SCG } \\ \text { Methylxanthines } & \text { Altered pharmacokinetics in pregnancy } \\ & \text { Animal studies - teratogenicity in high doses } \\ \text { Possible neonatal theophylline toxicity if used in third trimester } & \text { Caution in pregnancy } \\ \text { Leukotriene antagonists } & \text { Camited information available } \\ & \end{array}$

(oxygen saturation should be kept above 95\%). Treatment should ideally be in a high-dependency ward. If dehydrated, IV dextrose is preferable to normal saline (if not hyperglycaemic) and care is taken to avoid fluid overload and resulting pulmonary oedema as the mother's cardiac system is already hyperdynamic.

\section{LABOUR}

An attack during labour is less likely than at other times in pregnancy because of an increase in minute tidal volume, maternal plasma corticosteroids, prostaglandins and adrenaline. Exacerbations should be treated promptly with appropriate drugs, as uncontrolled asthma is far more likely to interfere with delivery. There is little firm evidence to suggest inhaled $\beta_{2}$-agonists used for asthma prolong labour.

Women taking systemic corticosteroids for greater than one month should receive $100 \mathrm{mg}$ hydrocortisone eight hourly from the onset of labour until they can take oral preparations again as this will prevent an Addisonian crisis.

\section{FOETAL MONITORING}

Optimal foetal assessment includes establishing gestational age, assessment of foetal growth and monitoring foetal activity. ${ }^{13}$

\section{CONCLUSIONS}

The overall risks of asthma in pregnancy are small and data are conflicting, ${ }^{12}$ but despite more available drugs, increased understanding and newer guidelines, pregnancies in asthmatic women are still associated with adverse outcomes. ${ }^{2}$ In accordance with published guidelines, ${ }^{14,15}$ a multidisciplinary approach is essential, with asthma and obstetric care being fully integrated. This includes monitoring of maternal symptoms and lung function as well as foetal growth and development. Treatment is essentially the same as in non-pregnant patients with a short-acting reliever medication and prophylactic medication as needed. To minimise risk, medication should be limited to those drugs with which we are most experienced. High-risk patients and those with continuing symptoms should be seen regularly.

References

1. Albert R, Spiro S, Jett J, editors. Comprehensive respiratory medicine. St Louis: Mosby Publishing; 1999

2. Alexander S, Dodds L, Armson B. Perinatal outcomes in women with asthma during pregnancy. Obstet Gynaecol 1998;92(3):435-40

3. Ebden P. Evans E. Management of asthmatic conditions in pregnancy. Prescriber 1996;7(5):21-9

4. Demissie K, Breckenridge MB, Rhoads GG. Infant and maternal outcomes in the pregnancies of asthmatic women. Am J Respir Crit Care Med 1998;158:1091-5

5. Greenberger PA, Patterson R. The outcome of pregnancy complicated by severe asthma. Allergy Proc 1988;9:539-43

6. Jana N, Vasishta K, Saha SC, et al. Effect of bronchial asthma on the course of pregnancy, labour and perinatal outcome. J Obstet Gynaecol 1995;3:227-32

7. Shatz M. Interrelationships between asthma and pregnancy: A literature review. J Allergy Clin Immunol 1999;103:5330-6

8. Schatz M, Zeiger RS, Hoffman CP, et al. Perinatal outcomes in the pregnancies of asthmatic women: A prospective controlled analysis. Am J Crit Care Med 1995;151:1170-4

9. British National Formulary. London: British Medical Association and Royal Pharmaceutical Society Of Great Britain;1999

10. Stenius-Aarniala BS. Hedman J, et al. Acute asthma during pregnancy. Thorax 1996;51(4):411-4

11. Schatz M, Zeiger RS, Harden K, et al. The safety of asthma and allergy medications during pregnancy. $J$ Allergy Clin Immunol 1997;100(3):301-6

12. Schatz M. Asthma and pregnancy. Lancet 1999;353:1202-4

13. Cousins L. Fetal oxygenation, assessment of fetal well-being, and obstetric management of the pregnant patient with asthma. J Allergy Clin Immunol 1999;103(Suppl 2):S343-9

14. Luskin AT. An overview of the recommendations of the Working Group on Asthma and Pregnancy. National Asthma Education and Prevention Program. J Allergy Clin Immunol 1999;103(Suppl 2):S350-3

15. British Thoracic Society, National Asthma Campaign, Research Unit of the Royal Physicians of London, et al. The British guidelines on asthma management. Thorax 1997;52:S1-21 